\title{
Aerosol Administration During Nasal CPAP in Newborns Can Be Optimized
}

Aerosols have proven to be an effective form of drug delivery. Nevertheless, the development of devices as well as medical agents for aerosolization to treat mechanically ventilated newborns still presents a substantial challenge. ${ }^{1}$ Low tidal volumes and functional residual capacity, high breathing frequency, short aerosol particle residence time, and small airway diameters cause low aerosol deposition in the lower airways in infants..$^{2-4}$ There are few clinical deposition studies in the neonatal population, because of the inability to use radio-labeled aerosols. ${ }^{5}$ However, despite the paucity of clinical data, aerosols have been used to treat critically ill newborn infants without a clear understanding of the optimal aerosol delivery system, the drug deposition pattern in the lung, and the dose/response relationship for aerosolized medications. A multi-center questionnaire-based study showed that aerosolized medications (eg, albuterol) are administered to infants with ventilator support as part of routine therapy. ${ }^{6}$ Nevertheless, none of the Cochrane Reviews recommend aerosol therapies to newborns during any type of ventilatory support. ${ }^{7-9}$

See the Original Study on Page 340

There has been a very visible shift in the early (just after delivery) modes of ventilatory support in newborns with respiratory failure, toward the use of "gentler" ventilation, based on recent multi-center clinical studies. ${ }^{10-12}$ Early intubation and prophylactic surfactant administration were shown not to be superior to early nasal CPAP in preventing bronchopulmonary dysplasia (BPD). It is important to mention that the study by Avery et al, already 3 decades ago, linked the use of nasal CPAP to lower risk of BPD. ${ }^{13}$ BPD is the most frequent serious complication of extremely premature birth. ${ }^{14}$ The pathogenesis of BPD is multifactorial and includes features related to structural and functional immaturity of the lungs, including inadequate antioxidant enzyme levels, deficient surfactant production (which make the lungs uniquely susceptible to volutrauma), oxygen toxicity, and lung inflammation, all of which compromise alveolarization. ${ }^{15}$ Several drugs (corticosteroids, antioxidants, diuretics, bronchodilators, inhaled nitric oxide, and surfactants), ${ }^{16}$ have been used for the prevention and treatment of BPD. Some of these agents were used in the aerosolized forms, and did not show the expected clinical effects, possibly because of suboptimal aerosol delivery during any type of ventilatory support.

Recent guidelines recommend noninvasive ventilation in infants even less than 30 weeks gestational age, ${ }^{17}$ and do not recommend any aerosolized agents to treat newborns on ventilatory support. ${ }^{7-9}$ There have been attempts, though, to establish solid grounds for aerosol therapy to prevent or treat BPD. One example is the multi-center, phase 3 Neonatal European Study of Inhaled Steroid (NeuROSIS) of early inhaled budesonide for BPD prevention. ${ }^{18}$

In light of these facts, the original study by Farney et $\mathrm{al}^{19}$ in this issue of Respiratory CARE fits perfectly into a so-called "unmet medical need." This in vitro study evaluated aerosol delivery with a vibrating-mesh nebulizer (Aeroneb Solo), an infant CPAP generator (CareFusion Infant Flow SiPAP), and a test lung. They tested 2 locations of the nebulizer (because no nebulizer position during CPAP with Infant Flow has been established as optimal): at the humidifier, and in the inspiratory limb, at $32 \mathrm{~cm}$ from the nasal prongs. The aerosol delivery and loss in the devices and circuit was measured with radio-labeled technetium and scintigraphy.

They found that placing the nebulizer closer to the patient significantly improved aerosol delivery. The majority of the drug loss occurred in the inspiratory limb and nebulizer when the nebulizer was located at the humidifier. These results are contrary to findings by Ari et al, who found that placing the Aeroneb nebulizer distally from the patient (before the humidifier) gave superior drug delivery. It is important to note that, though the breathing conditions were similar in the 2 studies, the tested bias flows were different: 2 and $5 \mathrm{~L} / \mathrm{min}$ with the Galileo versus $8 \mathrm{~L} / \mathrm{min}$ with the Infant Flow SiPAP. Other studies have found that bias flow and exhalation-valve function influence aerosol delivery, so each CPAP or noninvasive ventilation driver may have a different aerosol delivery profile. ${ }^{20,21}$

The second important finding from Farney et al is that, regardless of the nebulizer location, there was substantial aerosol deposition in the generator tubing and in the CPAP generator, which serves also as a patient interface. This part of the ventilator tubing plays a role in generating 
pressure as well as improving exhalation (via the Coanda effect), which decreases the work of breathing. ${ }^{22}$ This finding by Farney et al directs future improvements in aerosol delivery toward better designs of patient interfaces and ventilator connectors. This approach was already taken by Longest et al, who found better aerosol delivery with so called "streamlined" technology. ${ }^{23}$

In conclusion, the in vitro study by Farney et al shows that in the pediatric/infant population it is better to position a vibrating-mesh nebulizer proximal to the patient (with the Infant Flow SiPAP configuration it is $32 \mathrm{~cm}$ from the nasal prongs). Future engineering development should aim at improving the patient interface to limit turbulent flow and decrease aerosol deposition in this part of the circuitry. When optimal circuitry for noninvasive ventilation and aerosol delivery is developed, future clinical studies should focus on establishing the optimal aerosol particle size and inhaled dose. I strongly feel that the study by Farney et al brings us closer to successful aerosol therapy in newborns during noninvasive ventilatory support, and may decrease the risk of BPD.

\section{Jan Mazela MD PhD}

Department of Neonatology and Infectious Diseases Poznan University of Medical Sciences Poznan, Poland

\section{REFERENCES}

1. Mazela J, Polin RA. Aerosol delivery to ventilated newborn infants: historical challenges and new directions. Eur J Pediatr 2011;170(4): 433-444.

2. Fok TF, Monkman S, Dolovich M, Gray S, Coates G, Paes B, et al. Efficiency of aerosol medication delivery from a metered dose inhaler versus jet nebulizer in infants with bronchopulmonary dysplasia. Pediatr Pulmonol 1996;21(5):301-309.

3. Cole CH. Special problems in aerosol delivery: neonatal and pediatric considerations. Respir Care 2000;45(6):646-651.

4. Grigg, J, Arnon S, Jones T, Clarke A, Silverman M. Delivery of therapeutic aerosols to intubated babies. Arch Dis Child 199267 (1 Spec No):25-30.

5. Everard ML. Ethical aspects of using radiolabeling in aerosol research. Arch Dis Child 2003;88(8):659-661.

Dr Mazela has disclosed relationships with Discovery Laboratories, Dräger, Maquet, and Nutricia.

Correspondence: Jan Mazela MD PhD, Department of Neonatology and Infectious Diseases, Poznan University of Medical Sciences, Ulica Polna 33, Poznan 60535, Poland. E-mail: janco@pol-med.com.pl.

DOI: $10.4187 /$ respcare. 03160
6. Ballard J, Lugo RA, Salyer JW. A survey of albuterol administration practices in intubated patients in the neonatal intensive care unit. Respir Care 2002;47(1):31-38.

7. Shah SS, Ohlsson A, Halliday HL, Shah VS. Inhaled versus systemic corticosteroids for the treatment of chronic lung disease in ventilated very low birth weight preterm infants. Cochrane Database Syst Rev 2007;(4):CD002057.

8. Ng G, da Silva O, Ohlsson A. Bronchodilators for the prevention and treatment of chronic lung disease in preterm infants. Cochrane Database Syst Rev 2012;(6):CD003214.

9. Brion LP, Primhak RA, Yong W. Aerosolized diuretics for preterm infants with (or developing) chronic lung disease. Cochrane Database Syst Rev 2006;(3):CD001694.

10. Dunn MS, Kaempf J, de Klerk A, de Klerk R, Reilly M, Howard D, et al. ; Vermont Oxford Netwrok DRM Study Group. Randomized trial comparing 3 approaches to the initial respiratory management of preterm neonates. Pediatrics 2011;128(5):e1069-e1076.

11. Morley C, Davis PG, Doyle LW, Brion LP, Hascoet JM, Carlin JB; COIN Trial Investigators. Nasal CPAP or intubation at birth for very preterm infants. N Engl J Med 2008;358(14):700-708.

12. SUPPORT Study Group of the Eunice Kennedy Shriver NICHD Neonatal Research Network. Early CPAP versus Surfactant in extremely preterm infants. N Engl J Med 2010;362(21):1970-1979.

13. Avery ME, Tooley WH, Keller JB, Hurd SS, Bryan MH, Cotton RB, et al. Is chronic lung disease in low birth weight infants preventable? A survey of eight centers. Pediatrics 1987;79(1):26-30.

14. Hoekstra RE, Ferrara TB, Couser RJ, Payne NR, Connett JE. Survival and long-term neurodevelopmental outcome of extremely premature infants born at 23-26 weeks' gestational age at a tertiary center. Pediatrics 2004;113(1):e1-e6.

15. Kinsella JP, Greenough A, Abman SH. Bronchopulmonary dysplasia. Lancet 2006;367(9520):1421-1431.

16. Van Marter LJ. Epidemiology of bronchopulmonary dysplasia. Semin Fetal Neonatal Med 2009;14(6):358-366

17. Sweet DG, Carnielli V, Greisen G, Hallman M, Ozek E, Plavka R, et al. European consensus guidelines on the management of neonatal respiratory distress syndrome in preterm infants - 2013 update. Neonatology 2013;103():353-368.

18. Bassler D, Poets CF. Efficacy and safety of inhaled budesonide in very preterm infants at risk for bronchopulmonary dysplasia (NEuroSIS). http://clinicaltrials.gov/show/NCT01035190. 2009. Accessed Jan 6, 2014.

19. Farney KD, Kuehne BT, Gibson LA, Nelin LD, Shepherd EG. In vitro evaluation of radio-labeled aerosol delivery via a variable-flow infant CPAP system. Respir Care 2013;59(3):340-344.

20. Ari A, Atalay OT, Harwood R, Sheard MM, Aljamhan EA, Fink JB. Influence of nebulizer type, position, and bias flow on aerosol drug delivery in simulated pediatric and adult lung models during mechanical ventilation. Respir Care 2010;55(7):845-851.

21. Dai B, Kang J, Sun LF, Tan W, Zhao HW. Influence of exhalation valve and nebulizer position on albuterol delivery during noninvasive positive pressure ventilation. J Aerosol Med Pulm Drug Deliv 2013 [E-pub ahead of print].

22. Courtney SE, Pyon KH, Saslow JG, Arnold GK, Pandit PB, Habib $\mathrm{RH}$. Lung recruitment and breathing pattern during variable versus continuous flow nasal continuous positive airway pressure in premature infants: an evaluation of three devices. Pediatrics 2001;107(2): 304-308.

23. Longest PW, Golshahi L, Hindle M. Improving pharmaceutical aerosol delivery during noninvasive ventilation: effects of streamlined components. Ann Biomed Eng 2013;41(6):1217-1232. 